\title{
Metrópoles brasileiras: a ação dos coletivos de comunicação contra a barbárie na retomada do espaço público
}

\author{
Raquel Paiva \\ Universidade Federal do Rio de Janeiro \\ paivaraquel@hotmail.com \\ Marcello Gabbay \\ Universidade Federal do Rio de Janeiro \\ marcellogabbay@uol.com.br \\ Luciana Gouvêa \\ Universidade Paulista \\ lucigouveiac@gmail.com
}

Recibido: 31/7/2018 / Aceptado: 9/11/2018

doi: 10.26439/contratexto2019.n031.3887

\begin{abstract}
Resumo. Este texto pretende discutir, a partir da premissa básica da necessidade do real uso da cidade pelos seus habitantes e da comunicação como dispositivo de inserção e mobilização do espaço público, situações como a impossibilidade da circulação pelas ruas, o confinamento e segregação de populações a áreas definidas, o não acesso aos bens públicos, e finalmente o confronto com a violência policial como forma de desmobilização dos bairros periféricos. A partir de uma breve discussão sobre o conservadorismo e o racismo como cenário estrutural da realidade brasileira, apresentamos uma análise do modelo de ação comunicacional adotado por dois coletivos brasileiros no atual cenário de precarização dos espaços públicos, o coletivo Papo Reto (Rio de Janeiro, Sudeste) e o Tela Firme (Pará, Norte). Estes grupos têm em comum o lugar de fala a partir das periferias dos grandes centros urbanos, e também o questionamento das formas de ocupação das cidades em temas como violência, moradia e cultura. A perspectiva é que esse texto aponte para um espírito das cidades baseado na noção coletivista da polis e do bem comum, em substituição a uma visão particularista e conservadora dos espaços. Acredita-se que esses coletivos promovem formas de ocupação urbana baseadas na visão de construção de uma cidade mais humana e igualitária - o que inclui toda gama de afetos e embates da vida em comum.
\end{abstract}

Palavras-chave: comunicação / coletivos urbanos / espaços públicos / direito à cidade. 


\section{Metrópolis brasileñas: la acción de los colectivos de comunicación contra la barbarie en la recuperación del espacio público}

Resumen. Este texto pretende discutir, a partir de la premisa básica de la necesidad del uso real de la ciudad por parte de sus habitantes y de la comunicación como dispositivo de inserción y movilización del espacio público, situaciones como la imposibilidad de la circulación por las calles, el confinamiento y segregación de poblaciones a áreas lejanas, el no acceso a los bienes públicos y, finalmente, la confrontación con la violencia policial como forma de desmovilización de los barrios periféricos. A partir de una breve discusión sobre el conservadurismo y el racismo como escenario estructural de la realidad brasileña, presentamos un análisis del modelo de acción comunicacional adoptado por dos colectivos brasileños en el escenario actual de precarización de los espacios públicos, el colectivo Papo Reto (Río de Janeiro, Sudeste) y el colectivo Tela Firme (Pará, Norte). Estos grupos tienen en común su lugar de enunciación desde las periferias de los grandes centros urbanos y también el cuestionamiento de las formas de ocupación de las ciudades a partir de temas como la violencia, la vivienda y la cultura. La perspectiva es que este texto apunte hacia un espíritu de las ciudades basado en la noción colectivista de la polis y del bien común, en sustitución de una visión particularista y conservadora de los espacios. Se considera que estos colectivos promueven formas de ocupación urbana basadas en la visión de la construcción de una ciudad más humana e igualitaria, lo que incluye toda la gama de afectos y embates de la vida en común.

Palabras clave: comunicación / colectivos urbanos / espacios públicos / derecho a la ciudad 


\section{Brazilian metropolises: communication groups' actions against barbarism in the reoccupation of public spaces}

Aвstract. This paper aims to discuss situations such as the impossibility of free circulation in the cities, the confining and segregation of the population to peripheral areas, the lack of access to public spaces, and finally the confrontation with police violence as a way to immobilize peripheral neighborhoods, through the basic premise of the need for the real use of the city by its people, and communication as a tool of inclusion and mobilization in public space. Beginning with a brief discussion about racism and conservatism as a structural scenario of the reality of life in Brazil, we present an analysis of the communication model adopted by two Brazilian groups in the current context of public spaces' precariousness: the Papo Reto group (Rio de Janeiro, Southest) and the Tela Firme group (Pará, North). These groups share their discourse production from the peripheral areas of great urban centers, as well as the questioning of how cities have been occupied from the violence, dwelling and culture points of view. The purpose of this paper is to draw a spirit of citizenship inspired by the collectivist notion of polis and commonwealth, as a substitute to a particularistic and conservative vision of the city. We believe that these groups promote ways of urban occupation based on the will to build a more humanized and equal city which includes all kinds of affections and struggles of everyday life.

Keywords: communication / urban groups / public spaces / right to the city 
\#ParemDeNosMatar / E isso não é um pedido: / É uma ordem! / Uma ordem dada contra esse racismo em lata / Servido a nós diariamente como ração / Em pratos de alumínio, ódio e trauma / Por entre as grades do presídio, / da escola ou da televisão / Caldo podre requentado nas panelas brancas do assédio, / do genocídio, I da precarização, / da folclorização midiática, / da apropriação cultural, / da criminalização! (...) / \#ParemDeNosMatar / E isso não é um pedido: /

um giro organizativo! / Conectando quebradas, /

Quilombos, coletivos, arsenal negro de alto impacto sensitivo /

Marginal, ostensivo, altivo / Resistiremos /

Permanecendo / Vivas e Vivos /

Lançando bombas de Literatura, Cinema, Rap, Pixo! /

Bum bum clap / Bum bum clap / Você está ouvindo? /

\#ParemDeNosMatar / E isso não é um pedido.

Felipe Estrela (2016)

\section{Introdução}

s cidades brasileiras - tanto as megalópoles, como Rio de Janeiro e São
Paulo, como as cidades de porte médio - enfrentam neste novo milênio a
degradação como uma forma que se instalou não apenas nos equipamentos urbanísticos, mas também como um modo de vida no qual o confinamento tem se tornado ora uma opção ora uma imposição. A gentrificação como modelo adotado para os grandes eventos, as inúmeras remoções de moradias, a re-edição do ideário da limpeza no urbanismo e o contínuo investimento no deslocamento via automóvel privado acentuaram, nas últimas décadas, a segregação de espaços públicos. Este texto pretende discutir, a partir da premissa básica da necessidade do real uso da cidade pelos seus habitantes e da comunicação como dispositivo de inserção e mobilização do espaço público, situações como a impossibilidade da circulação pelas ruas, o confinamento e segregação de populações a áreas definidas, o não acesso aos bens públicos e, finalmente, o confronto com a violência policial como forma de desmobilização dos bairros periféricos.

A comunicação tem desempenhado historicamente um papel fundamental não apenas nos estudos e nas análises da cidade, desde a Escola de Chicago, passando pelos latino-americanos Jesús Martín-Barbero, Néstor García-Canclini, Muniz Sodré, entre outros, já se apontavam, em seus estudos, a desagregação do social em função do continuo investimento na fragmentação e no fluxo, e a necessidade de um "novo sensorium" capaz de aglutinar e de produzir o "espaço comum", aquele onde podem se desenvolver as relações produzidas 
pelas práticas comuns ou comunitárias. Neste sentido, este texto, além de promover uma descrição da situação atual das cidades brasileiras, analisa práticas de coletivos urbanos que propõem uma reversão a partir do caráter gregário de práticas de ocupação espacial, apontando também novos usos para a utilização da virtualidade. A função dos coletivos independentes de comunicação, formados por jornalistas, ativistas e representantes da sociedade civil, é promover um olhar crítico sobre as estratégias de precarização dos espaços da cidade implementadas pelo poder público com o desinvestimento dos espaços de encontro como ruas, praças e prédios públicos, que sucumbem à ocorrência das violências urbanas e impõem à população, em especial a de baixo poder aquisitivo, o confinamento em seus bairros, reforçando a reprodução das desigualdades socioeconômicas no país. Este cenário é recorrente em todos os países do hemisfério sul, em especial na América Latina, onde os índices de violência urbana, falta de saneamento e precarização dos espaços públicos ajudam a consolidar um modelo de cidade marcado pela segregação espacial. O que sustenta este apartheid $^{1}$ contemporâneo é a formulação e disseminação de um ideário de cidade e cidadania elaborado no âmbito da grande mídia, que inclui desde o jornalismo até o cinema e a música popular.

Desta forma, acreditamos que a ação comunicacional de coletivos situados em áreas periféricas das grandes cidades pode sugerir modelos interessantes para a retomada dos espaços por meio da comunicação e da produção de vínculo, especialmente no atual cenário de conservadorismo e precarização dos espaços públicos. É o caso dos dois grupos analisados neste artigo, o coletivo Papo Reto (Rio de Janeiro) e o Tela Firme (Pará). Apesar de atuarem em regiões distintas do país, a Norte e a Sudeste, estes grupos têm em comum o lugar de fala a partir das periferias dos grandes centros urbanos, e também o questionamento das formas de ocupação das cidades em temas como violência, moradia e cultura. A abordagem metodológica para a análise destas duas experiências foi o estudo de caso com pesquisa de campo e, no caso do Tela Firme, o uso de entrevistas em profundidade. As coletas e observações foram feitas ao longo do ano de 2017, como parte da pesquisa de Mestrado de uma das autoras (Gouvêa, 2018). No caso do coletivo Papo Reto, a metodologia foi amparada na pesquisa documental em materiais produzidos pelo próprio grupo e pela imprensa, com o objetivo de obter um comparativo com o caso do Tela Firme.

1 Expressão em africâner que significa "separação". Ela está ligada ao sistema de segregação racial adotado na África do Sul entre os anos de 1948 a 1994, no qual os brancos tinham privilégios. Atualmente, é utilizada para nomear qualquer tipo de segregação social em que há a proposital intenção de separar pessoas ou classificá-las como melhores ou piores em função de seu status social. 
A perspectiva é que esse texto aponte para um espírito das cidades baseado na noção coletivista da polis e do bem comum, em substituição a uma visão particularista e conservadora dos espaços. Acredita-se que os coletivos independentes de comunicação a serem analisados possuem um discurso voltado para o reconhecimento crítico da decadência dos espaços públicos. Isto significa estabelecer conexão direta entre a decadência e as formas consensualmente difundidas principalmente pela mídia massiva de segregação espacial. Norteia ainda a proposta deste texto, a ideia de que esses coletivos promovem formas de ocupação urbana baseadas na visão de construção de uma cidade mais humana e igualitária - o que inclui toda gama de afetos e embates da vida em comum. Para isso, é preciso compreender antes alguns aspectos que configuram o cenário de conservadorismo estrutural onde se inserem hoje as lutas pela cidade no Brasil.

\section{Conservadorismo e Cidade no Brasil: entre a semelhança e a diferença}

Entre o final de 2017 e o início de 2018, uma pesquisa indicava o Brasil como o país que mais mata lideranças ligadas aos Direitos Humanos na América Latina. Divulgada pelo Business and Human Rights Resources Center (Chade, 2018) ela vem sendo divulgada na imprensa toda vez que algum fato ligado ao rechaço dos direitos humanos ressurge na mídia, como aconteceu com o caso do assassinato da vereadora do Rio de Janeiro Marielle Franco (PSOL-RJ), no dia 14 de março de 2018. A mesma pesquisa do instituto britânico aponta, ainda, que o Brasil vem ocupando o topo do ranking nos últimos três anos. As disputas de terra, o engajamento de movimentos sociais pela garantia de direitos no campo e na cidade acarretam mais mortes de ativistas no Brasil do que na Colômbia, no Peru, no México e na Índia, países que vivem cenários de desigualdade semelhante.

Este dado está ligado ao histórico de desigualdade social, econômica e cultural que marca a constituição da sociedade brasileira, o que creditamos ao espírito conservador sobre o qual se inventa a vida brasileira. As bases da sociedade moderna no Brasil têm no escravismo e no racismo um sustentáculo determinante; de tal forma que o pensamento escravocrata e apartador, que definiu a vida social no século xIx, está enraizada na base de discursos e movimentos que resistem à superação da sociedade de castas criada no Brasil rural. É o caso, por exemplo, das reações contrárias à promulgação da Lei Complementar n. 150 (2015) que regulamenta o trabalho doméstico no Brasil, atribuindo a esta categoria regulação sobre a jornada trabalhada, idade mínima, e sobre o recolhimento de fundo de garantia e previdência social, dentre outros direitos. No dia 27 de março de 2013, quando a Lei da Doméstica ainda constava como Proposta de Emenda Constitucional, a Folha/UOL publicou uma matéria com o sociólogo da UnB Joaze Bernardino Costa (Da Agência Brasil, 2013) para analisar a intensa 
reação, nas redes sociais, de parte da sociedade que acreditava que o novo conjunto de direitos trabalhistas poderia servir para inibir as ofertas de trabalho para domésticas, dada a oneração para os patrões. Tal discurso remonta à reação anti-abolicionista no final do século XIX, quando jornais como o Diário de Notícias, publicaram análises sobre a inconstitucionalidade da Lei Áurea, já que a libertação dos escravos poderia resultar num encarecimento da mão de obra e na diminuição do trabalho (Machado Da Silva, 2017, pp. 28-37).

O pensamento conservador como criador de uma visão de cidade baseada no progresso, na ordem e no mérito de classe não anda separado dos vários tipos de racismos, que Sartre vê como um projeto político travestido de paixão coletiva. A respeito do antissemitismo e do efeito avassalador com que o racismo se espalhou pela Alemanha nazista, o estudo de Sartre ([1954] 2005, p. 9-12), chama a atenção para a classificação do racismo na forma de opinião, por sugerir que o pensamento racista de toda ordem possa atribuir para si a qualidade de mero ponto de vista, gosto, preferência e, em última instância, um direito à liberdade de opinião. Ao contrário, Sartre define este tipo de postura como paixão, numa categoria inferior ao pensamento. A paixão coletiva com que se inventam critérios de distinção racial que irão sustentar uma distinção de direitos passa por um processo de legitimação quando utilizados como argumento pelas instâncias conservadoras da sociedade. A repulsa pelo outro é, no fim das contas, uma invenção político-cultural que define critérios fenotípicos, comportamentais, de crença, etc., a fim de dar sentido a uma determinada estrutura de apartheid social ou de classe. Da mesma forma que se inventou na Alemanha nazista o mito do judaísmo como categoria inferior, ainda hoje se sustentam em várias sociedades do Ocidente mitos racistas sobre o negro, o chinês, o árabe, o mulçumano; todas, culturas cujos representantes são considerados pelo pensamento hegemônico como "o outro" que deve ser evitado. Sobre o antissemitismo, ideia radical que levou ao extermínio de aproximadamente seis milhões de judeus. Sartre, "O que é essencial não é o 'dado histórico', mas sim a ideia que os agentes da história erigiram para si sobre o judeu" (2005, pp. 17-18). Com isso, o filósofo define o racismo nazista como paixão, e como tal configura-se um fenômeno de grande aderência coletiva. O racismo, o eugenismo e a gentrificação são por vezes projetos políticos forjados na história pelos interesses do capital, mas que são "consumidos" na sociedade média como dispositivo passional, daí seu efeito prático de desarticulação ou de rearranjo da vida nos bairros e nas cidades.

"É que todo e qualquer racismo exacerbase precisamente no instante da proximidade", afirma Muniz Sodré (2017, p. 92) em seu mais recente livro, que trata do processo secular de invisibilização do pensamento filosófico africano. Entre o século xIX; passando pelas insurgências avassaladoras do racismo na Alemanha, nos Estados Unidos e na África do Sul; até os dias atuais irmana-se um pensamento 
conservador que reivindica os espaços coletivos, os salões, as escolas, as universidades, os passeios públicos e as praias com um olhar exclusivista. A apropriação da cidade serve ao interesse eugenista das elites, mas se ampara numa ideologia contrária à ideia de polis como espaço público. São vários os fatores que provocam esta quebra no sentido político grego de cidade, como a burocratização dos Estados, a ascensão do modelo capitalista e a comunicação de massa, por exemplo. Porém, o efeito provocado nos novos arranjos de cidade, hoje propostos como projetos governamentais como é o caso do programa "SP Cidade Linda"2 da prefeitura de São Paulo, vai além dos quesitos econômicos e sociais. Neste caso, a logomarca "SP Cidade Linda" da gestão de João Doria na Prefeitura de São Paulo foi a bandeira de um programa de zeladoria que incluía, dentre outras metas, a "limpeza" de grafites nos paredões da Avenida 23 de Maio, uma das principais vias de escoamento da cidade, tradicionalmente ocupada por arte urbana; e a remoção de programas sociais na conhecida "cracolândia" do bairro da Luz, provocando um efeito em cadeia de multiplicação de zonas de consumo de crack no centro da cidade. Há uma perda na relação afetiva e psíquica com o espaço e com o outro (Paiva e Gabbay, 2016). Uma cidade construída sob uma ordem de repressão - toques de recolher, violência policial, suspensão de programas sociais e culturais, encarecimento dos transportes coletivos, etc - resulta em uma sociedade marcada pela falência dos dispositivos psico-afetivos de vínculo, como a solidariedade e a empatia. A desterritorialização do outro, ou sua reclusão em espaços periféricos, resulta para Sodré (2017, p. 93) da ideia de semelhança como proximidade. O "outro" é uma ameaça constante à divisão dos espaços hegemônicos.

Um dos exemplos recentes deste fenômeno é as imagens divulgadas na mídia de soldados do Exército brasileiro utilizando telefones celulares para realizar o fichamento de moradores da Vila Kennedy, Zona Oeste do Rio de Janeiro, durante a intervenção militar na região, em fevereiro de 2018. A ação visava verificar os antecedentes criminais de quem entrava e saía da favela, irrestritamente. A medida, deliberada e autoritária, definida unilateralmente pelos poderes policiais e militares, logo foi questionada no âmbito jurídico. A Defensoria Pública do Estado acusou o Exército de incidir no constrangimento ilegal da população, pois mediante a apresentação do documento de registro civil, não há o direito de se fazer fotografias aleatórias dos transeuntes.

Por outro lado, está o ideal humanista que, sustentado na filosofia do vínculo, tende a pensar a cidade como espaço democrático para a produção da diferença.

2 A logomarca "SP Cidade Linda" foi inclusive objeto de acusação de improbidade por parte do Ministério Público Estadual por associar um programa de zeladoria da Prefeitura à imagem pessoal do prefeito em uma possível ação de marketing (Lobel, 2018). 
O filósofo alemão Friedo Ricken (2004, p. 110) recupera o ideal aristotélico: “o verdadeiro ser do ser humano é ser para o outro", onde estariam as bases do bemviver coletivo, fundamento da polis. Viver para o outro por necessidade material e por necessidade essencial. A vida em comum foi pensada a partir da ideia de que mesmo em uma perspectiva egoística o eu só tem sentido em relação com o outro. A amizade, como maior bem humano, faz da ideia de comunidade um valor fundamental da ética aristotélica, sendo a comunidade alimentada pelas trocas e pela busca por igualdade (Ricken, 2004, pp. 121-124). Assim, a comunidade funciona no desejo por equilíbrio e reconhecimento mútuo.

A convivência desigual, sustentada pela opressão, não compõe o ideal fundamental do bem-viver, segundo Ricken (2004, p. 135). O senso de igualdade e justiça na polis é fundamental para a busca do equilíbrio. Ricken (2004, p. 151) traduz este pensamento da Ética a Nicomaco como uma forma de "comunidade solidária"; onde a felicidade, desejada como bem supremo, deverá ser encontrada tanto junto à comunidade próxima, família e amigos, como junto aos concidadãos (Aristóteles [1097b], 2007, pp. 25-26). A vida na polis seria assim marcada pela busca do bem-viver, do meu e o do outro.

Numa perspectiva mais contemporânea, vale ressaltar a proposição de uma comunidade "pós-social" de Martin Buber (2008), ancorada na relação mais instintiva e criativa entre as pessoas e baseada na relação de sentido entre o eu e o $t u$. A esta forma de relação não atribuímos uma tonalidade romântica. Ao contrário, superado o idealismo aristotélico que ainda assim forneceu as bases de um desejo por uma polis baseada na relação e na solidariedade, pensamos a vida nas cidades como a possibilidade do confronto. O que há de diversidade na cidade o próprio sentido do outro - é a possibilidade de inclusão da negatividade. "Onde vige o puramente positivo, o excesso de positividade, ali não há espírito", afirma o filósofo coreano Byung-Chul Han (2012, p. 46). O autor está se referindo a perda do eros na vida social.

O neoliberalismo, com seus impulsos do eu e de desempenho desenfreados, é uma ordem social da qual o eros desapareceu totalmente. A sociedade da positividade, donde se ausentou a negatividade da morte, é uma sociedade do mero viver, dominada pela única preocupação de "assegurar a sobrevivência na descontinuidade". (Han, 2012, p. 52)

Se, por um lado, é pertinente a crítica a uma ideia de cidade sustentada sobre uma positividade "pura", marcada pelo desejo do progresso, da aniquilação da feiura, da imagem da miséria (e não da miséria estrutural), pela renovação imobiliária que suplanta a memória arquitetônica dos centros urbanos, e pelas medidas eugenistas que vão desde a privatização dos transportes, parques e espaços públicos, até o modelo repressivo de policiamento nos eventos coletivos 
e nos bairros periféricos; por outro lado, o eros como domínio sombrio da vida coletiva, como impulso criativo e contato vital, ressurge na forma de movimentos de resistência. Neste contexto, quais são as estratégias de enfrentamento dos coletivos de comunicação no Brasil à ascensão do pensamento conservador? Veremos dois exemplos a seguir:

\section{Tela Firme: Chega de extermínio!}

Alguns dos aspetos centrais da ação de coletivos de comunicação independente que colaboram na retomada dos espaços públicos são a proposição de outras imagens de representação da população e dos territórios em que atuam, que se opõem às imagens apresentados pelas mídias comerciais, muitas vezes estereotipadas ou fragmentárias; e, além disso, o fato das ações destes coletivos serem, por vezes, um convite aos encontros e às convivências que se dão nos territórios.

Para tanto, a manutenção de grupos de WhatsApp, páginas do Facebook, além da mobilização e da articulação presencial junto aos moradores da periferia a partir da oferta educativa e cultural dos quais emergem espaços híbridos de interação, são algumas das estratégias de facilitação, aproximação e multiplicação da ação sociocultural e política destes coletivos que assumem a posição de protagonismo frente à necessidade de se ter uma mídia local mais humanizada e que seja sensível aos variados problemas que atingem as populações periféricas.

O coletivo de comunicação popular Tela Firme segue esta linha de atuação. O grupo se reuniu em março de 2014 com a finalidade de construir formas positivas de representação sobre o bairro da Terra Firme, em Belém, Estado do Pará, Norte do Brasil, elaborando e executando reportagens cujo foco era a programação cultural e os projetos sociais do território. O formato de mídia inicialmente foi o de uma TV na internet, cujos vídeos eram postados na plataforma YouTube (www.youtube.com/channel/UCqWGBbmj6LcE-Zlp_2pcFEA).

Entre as primeiras pautas do grupo está o carnaval promovido pelas escolas de samba locais - salientando desde então as práticas de ocupação e ressignificação das vias públicas deste bairro que é historicamente conhecido pelo risco, perigo e falta de estrutura urbanística -; a feira, sua variedade de produtos regionais e as sugestões de feirantes, crianças e moradores do bairro para melhorar a infraestrutura do espaço; entrevistas com candidatos ao governo do Estado; e a necessidade da construção de equipamentos de lazer para a juventude. Apesar da produção audiovisual em questão ter o viés crítico e propositivo das melhorias necessárias aos espaços em comum, ela também mostra seus aspectos positivos e atrativos, seus pontos de convergências, como por exemplo os eventos culturais, as zonas comerciais caracterizadas pelos seus preços em conta que atraem moradores de outros bairros da cidade e a 
programação da igreja que propõe atividades gratuitas durante o carnaval para crianças e adolescentes.

Uma chacina ocorrida em Belém no dia 4 de novembro de 2014 que resultou no assassinato de dez jovens de bairros periféricos da cidade, como retaliação pela morte de um policial militar, levou o coletivo Tela Firme a se inserir no debate sobre Direitos Humanos ${ }^{3}$. Começou a realizar cobertura jornalística e cultural de protestos e ações sociais, fazendo articulações políticas para gerar dados sobre a criminalidade e construiu uma rede colaborativa de promoção da cultura de paz e de ajuda às famílias das vítimas de crimes violentos em bairros de periferia, em especial na Terra Firme.

Naquele dia, houve registro de execução de jovens nos bairros Terra Firme, Marco, Jurunas, Tapanã e Sideral. Como já foi amplamente apurado pelo governo e pelas mídias locais, a motivação para esses assassinatos em série foi a morte de um cabo da polícia militar, Antônio Marcos da Silva Figueiredo, de 43 anos, conhecido como "Pety", que também tinha envolvimento com o crime organizado (Portal G1, 2015a) em Belém. Conforme citam Amorim, Sousa, Mota e Silva (2015, p. 11), logo após da notícia da morte, começaram a surgir, no Facebook e no Twitter, informações de que milícias ${ }^{4}$ foram em busca dos criminosos na periferia da cidade e que estavam matando pessoas pelas ruas como forma de vingança. Os comentários foram diversos assim como o número de mortes que passavam de trinta. Fotos de corpos foram compartilhadas através do aplicativo de conversa WhatsApp. A chacina foi o principal tema a ser discutido em redes sociais e chats de conversa ao longo do mês de novembro de 2014. De acordo com o relatório final da Comissão de Inquérito Parlamentar (CPI) das Milícias (Alepa, 2014, p. 72), o número oficial de pessoas assassinadas por milicianos foi dez.

As medidas de cerceamento ao espaço público impostas pela Polícia Militar iam então da "ronda", que resultou na chacina de 4 de novembro, à imposição de um "toque de recolher" não oficial, desmentido pelas fontes do Governo, mas verificado pelos moradores do bairro. Ainda, a invisibilização dos fatos ocorridos por meio do silêncio da mídia serviu como estopim para a criação de um vídeo documentário independente, cujo objeto não era apenas a produção de uma

3 Alguns membros do grupo já eram militantes da comunicação popular e de ações ligadas à cultura de paz antes do Tela Firme.

4 Na conceituação da CPI das Milícias, milícias são "grupos criminosos os quais contêm ou não a participação de agentes do sistema de segurança pública num determinado espaço: bairro, cidade, região. Simulando 'poder de polícia', através da venda de 'proteção' e tendo como condutas criminosas mais comuns a prática do extermínio, a extorsão mediante sequestro, e a associação para o tráfico de drogas. Independente do nível ou estágio de organização e sofisticação" (Alepa, 2014, p. 217). 
reportagem formal, mas sim a vazão das angústias, desejos e formas de dizer dos moradores da Terra Firme. O vídeo "Poderia ter sido você" faz um resgate histórico das chacinas que ocorreram em Belém de 1994 a 2014, totalizando um apanhado de quatro assassinatos em massa, os que tiveram maior repercussão midiática ao longo de todos esses anos.

Uma medida importante para o maior esclarecimento do caso foi a criação da CPI, instaurada na Assembleia Legislativa do Pará no final de 2014. Em seu relatório de conclusão foi realizado um mapeamento do modus operandi das milícias em atuação na cidade, inclusive com o grampo de ligações telefônicas autorizadas pela Justiça e oitivas com lideranças comunitárias e oficiais da Polícia Militar que, em depoimentos anônimos, relataram as práticas dessa modalidade criminosa. Como recomendação para a promoção de uma cultura de paz, o documento aconselhou o subsídio público às iniciativas culturais, sociais e aos coletivos de comunicação popular, a exemplo do Tela Firme, nos bairros mais vulneráveis a ocorrência dessas chacinas ${ }^{5}$.

Poucos dias após a chacina, os moradores da Terra Firme que conheciam o trabalho do coletivo começaram a cobrá-los no sentido de que uma cobertura jornalística ou uma "resposta" precisava ser dada pelo Tela Firme. Eles, na mesma noite, já haviam pensado no que fazer, nos próximos passos, e já tinham decidido fazer alguma ação, mas sem muita nitidez do que seria realizado de fato. De acordo com Francisco Batista, o principal articulador do coletivo, a ideia de fazer uma reportagem tradicional, com linguagem jornalística era algo a ser descartado: todos estavam com muito medo de criticar abertamente a chacina ocorrida e, ainda, não queriam fazer com que as famílias revivessem o trauma ao relatar a tragédia.

Eu imaginei assim: vamos nos colocar na situação. A gente teria condições de acessar as famílias tranquilamente, porque a ouvidora e eu fomos os primeiros a checar a situação delas, ir na casa delas... Aí foi interessante a sacada que a gente teve. A gente vai ser a vítima, vamos ser as vítimas, vamos sentir na pele o que foi que sofreu aquela vítima. Ainda emociona. O Maílson, de forma muito brilhante e sensível, aplicou os recursos de imagem e de trilha sonora. Deu certo, infelizmente para retratar algo tão triste e tão lamentável. (F. Batista, comunicação pessoal, 19 de junho de 2017).

5 No relatório final da CPI, recomenda-se: “XXV - Recomendar a Secretaria de Estado de Cultura identificar, fomentar e fortalecer iniciativas de projetos de Comunicação Social como o projeto Tela Firme, e dos Jovens Comunicadores da Amazônia no Pará" (Alepa, 2014, p. 219). A Jovens Comunicadores da Amazônia é uma agência de notícias mantida pela ONG Universidade Popular (Unipop). 
O formato escolhido para o video documental do Tela Firme foi a dramatização dos fatos, onde os atores (amadores) encarnavam a personagem póstuma de cada uma das vítimas da chacina. Dar voz àqueles que foram calados pela ação da violência instituída nas periferias é uma estratégia de humanização e de aproximação.

Sobre a expansão da criminalidade, Baitello Jr. (1999, p. 82) nos alerta que a violência urbana também tem raízes comunicacionais ligadas à perda de proximidade entre as pessoas. Essa perda é fomentada não somente por, mas também pelo excesso de mediação dos meios de comunicação, com as suas imagens distanciadas e juízos de valor pré-fabricados que impedem a manifestação do pensamento crítico (Debord, 1997; Anders, 2007; Flusser, 1985), da imaginação e do desenvolvimento da propriocepção - isto é, o sentido do próprio corpo e suas potencialidades de ação, conforme Baitello Jr. (1999):

Os sentidos da proximidade, em particular no sentido do tato, têm sido considerados toscos, e quando muito, auxiliares menores do conhecimento racional. As linguagens do tato e a comunicação tátil circunscreveram-se a áreas de refúgio, sendo desenvolvidas apenas quando da perda da visão ou então como terapias específicas, destinadas a excepcionalidades patológicas. Sobre estas lesões, das quais o fenômeno da moderna violência urbana (incluindo-se aí também a violência doméstica) faz parte, já se teceram muitas considerações, sobretudo a respeito das suas raízes socioeconômicas. O que pouco se considerou foi o fenômeno da violência sobre o ponto de vista de suas raízes, por assim dizer, comunicacionais, em outras palavras, como e por que desenvolvese uma tipologia de códigos comunicativos da violência, e se estes códigos tem a ver com a crescente perda da proximidade [...]. (Baitello Jr., 1999, p. 82)

Tendo em vista a linguagem da violência dada nos acontecimentos e em suas respectivas coberturas midiárias, o coletivo encontrou, por vias distintas e de oposição ao discurso fomentado pela grande mídia (de que as mortes nos bairros de periferia se justificam por seus altos índices de criminalidade), uma forma de transformar a tristeza, a raiva e a desesperança oriundas dessa perda de proximidade em arte, e o resultado está longe do relativismo: ele é perturbador - delineando as ideias a partir das relações de vínculo e empatia, que já se evidenciam desde o nome escolhido para a produção audiovisual, "Poderia ter sido você", convidando, assim, seus espectadores a uma reflexão séria, profunda e contundente sobre as violências urbanas.

A partir do lançamento do vídeo "Poderia ter sido você", publicado na plataforma YouTube em 6 de janeiro de 2015, o grupo passa a ter uma atuação mais constante no âmbito dos direitos humanos, participando mais intensamente dos debates contra o extermínio da juventude negra e periférica (Portal G1, 2017) e mediando discussões em escolas públicas, espaços culturais e na Universidade Federal do Pará. 
A gravação do vídeo ocorreu em dois dias, em uma sala emprestada pela Igreja de São Domingos de Gusmão. Os integrantes do coletivo chamaram alguns amigos que tinham alguma experiência com teatro, alguns deles eram do Grupo Jave, outros do teatro Ribalta (que está situado no bairro) e do curso de teatro da ONG Unipop.

Não obstante, a humanização das vítimas tende a ser negada quando os crimes ocorrem na periferia. De acordo com o relatório final da CPI das Milícias, em seu capítulo 12, em que discorre sobre "Considerações sobre o papel da mídia na legitimação da violência e a cultura dos heróis do povo", o recorte midiático leva em consideração a origem socioeconômica dos acusados:

É plenamente perceptível que quando o crime (em geral, latrocínio) ocorre em bairros de classe média, com vítimas pertencentes à classe média, as imagens são mais amenas, ou seja, mostra-se um respeito maior pelo corpo, pela vítima e pela família. Em vez de uma simples fotografia 3x4, a vítima é humanizada, ou seja, são divulgadas informações sobre quem era, onde trabalhava, onde morava, onde estudava, quais eram os planos de vida, etc. São divulgados detalhes da investigação e é comum haver novas reportagens sobre o assunto. (Alepa, 2014, p. 121)

Então, como observamos a necessidade de se promover a humanização também das vidas que foram ceifadas na periferia, o coletivo, para tratar da temática, precisou lançar mão de ferramentas artísticas, tomando de empréstimo técnicas teatrais e narrativa para manifestar o seu pensamento crítico.

O lançamento do vídeo "Poderia ter sido você" contou com a presença de familiares das vítimas das chacinas narradas pelo grupo. O evento teve a cober-

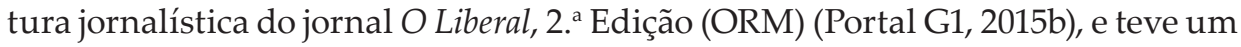
enfoque positivo a respeito do trabalho do coletivo. Além disso, eles foram no "Brasil Urgente" (RBATV), programa jornalístico de gerais que tem uma pitada de sensacionalismo. Francisco nos relatou que a ida à atração foi amplamente discutida e avaliada pelo coletivo, decidindo-se que valia a pena contrabalancear o discurso contra os direitos humanos que o programa costuma adotar.

Em 2015, a produção audiovisual foi exibida também na Assembleia Legislativa do Pará, durante a reunião da CPI das Milícias. Poucos meses depois, o grupo recebeu a "Comenda Paulo Frota", concedida por esta instituição a entidades, organizações e pessoas que militam em prol dos direitos humanos.

Dessa forma, a ação do grupo para protestar contra os crimes ocorridos na cidade, cuja culminância do processo foi o lançamento de um minidocumentário, gerou visibilidade, mas não apenas isso. $\mathrm{O}$ feito conseguiu apresentar os moradores da Terra Firme como produtores de cultura e de pensamento crítico, e que foram premiados por sua iniciativa de refletir sobre a violência nas periferias 
de Belém, rememorando histórias que poderiam ficar no esquecimento, não fosse o resgate narrativo proposto nessa produção, que reorientou a disposição dos corpos no espaço atingidos pela perda de proximidade e linguagens de violência para o protesto contra a realidade, para a ação social, para a convivência e para o debate de soluções nos territórios atingidos pela violência.

A partir destas ações, o grupo se configura como agente de mobilização e ocupação dos espaços públicos do bairro, pois utiliza seu poder de influência para colocar em pauta assuntos que atingem a comunidade como um todo, a exemplo das violências urbanas. Após atos criminosos e chacinas, a convivência em espaços públicos tende a rarear, por conta do medo que causa na população, principalmente em contextos periféricos, onde além do medo, as pessoas não têm acesso amplo a atividades culturais.

Consideramos que esta possibilidade de se estreitar os laços no contexto comunitário contribui para o avanço de direitos e da consolidação de narrativas que fortaleçam os vínculos, e que, portanto, gerem impacto nos espaços públicos do território, reabilitando-o como ponto de convergências e de encontros no bairro.

\section{Papo Reto: Parem de nos matar!}

No outro lado do país, no Rio de Janeiro, na capital carioca, que vive hoje um status de intervenção militar e de remoção de populações das periferias e das favelas, o coletivo Papo Reto iniciou as atividades no final de 2013, no Complexo do Alemão, Zona Norte do Rio de Janeiro. Formado por oito ativistas, a ideia era realizar uma mobilização social em prol das famílias atingidas pelas chuvas e desabamentos nas comunidades do morro do Alemão. Além disto, outra missão definida pelo grupo era dar voz aos moradores das periferias do Rio de Janeiro, vítimas de violências cometidas pelos poderes policiais, fazendo coberturas jornalísticas ou denúncias a partir das mídias digitais e preservando a identidade dos denunciantes.

O trabalho do grupo chamou a atenção da Organização das Nações Unidas ONU. Em 2015, eles foram convidados a participar do painel "Auto-representação como estratégia de combate do racismo", na sede da entidade, em Nova York. A atuação deles também despertou o interesse da TV Al Jazeera, que gravou um documentário (Al Jazeera, 2015) sobre as atividades do coletivo. Não obstante, o Papo Reto tem o apoio técnico da ONG norte-americana Witness, que auxilia ativistas de vários países a realizarem com segurança a produção de vídeos como ferramenta de defesa e denúncia em zonas de conflito.

O nome do coletivo é uma alusão à gíria carioca "mandar um papo reto", ou seja, falar sem "papas na língua", sem rodeios. Porém, o trabalho do grupo se dá 
em três frentes principais: ações de visibilidade e resolução de problemas para a população do Alemão; cobertura jornalística de operações policiais, conflitos armados; e denuncias sobre os abusos de poder dos agentes de segurança pública.

De acordo com os membros do coletivo, os objetivos deles são "fortalecer a comunidade e a sua inserção na cidade" (Puff, 2015). O grupo se enxerga também como um "dispositivo de resistência" (Gianotti, 2016) ao atuar como um agente de articulação entre os moradores do território, instituições públicas e privadas, e sociedade civil.

O Papo Reto realiza coberturas jornalísticas de operações policiais, e mais recentemente, acompanha a intervenção militar no Rio de Janeiro, decretada pelo presidente Michel Temer no dia 16 de fevereiro de 2018. No site do grupo (https://100ko.wordpress.com/), há diversas reportagens e artigos de opinião sobre a atuação violenta da polícia na favela. Um dos exemplos de reportagem comunitária feita pelo coletivo foi sobre a morte do menino Eduardo Ferreira, de 10 anos, no Complexo do Alemão, em 2015, assassinado por policiais militares. No vídeo (Papo Reto, 2015), realizado pelo grupo, a mãe da criança baleada dentro de casa, se desespera, falando com o outro filho pelo celular.

A produção, de $2 \mathrm{~m} 44 \mathrm{~s}$, apresenta esse momento de dor, a fúria dos vizinhos, detalhes do corpo da vítima sendo recolhida pelo IML (Instituto Médico Legal) e, no final, a comoção da vizinhança pedindo por justiça. Nenhum repórter do grupo interrogou os familiares do menino para saber como estavam se sentindo ou querendo arrancar deles alguma declaração que pudesse ser utilizada a serviço do espetáculo jornalístico que vemos em certo tipo de cobertura policial, dos vínculos hipnóticos, fazendo com que aquela família revivesse a tragédia exclusivamente em favor da técnica jornalística.

Por outro lado, os telejornais populares, a exemplo do "Brasil Urgente" da Bandeirantes, se aproximam mais da linguagem que Muniz Sodré (2009, p. 15) aponta como influenciada pela ficção literária, "com vistas à criação de uma atmosfera semântica mais compreensiva". Essa "estética do realismo objetivo" do jornalismo, que se vale de uma encenação do real, busca no campo popular imagens fortes de dor e morte, cinematograficamente arranjadas com música e narração, para por fim produzir um "efeito de real" (Sodré, 2009, p. 154), que muitas vezes toma como objeto os dramas da população periférica.

A câmera funcionou como uma sutil observadora, que não comunica expressamente as suas impressões ou julgamentos sobre o caso; isto é, temos outra forma de reportar os fatos que transita entre o sensível, pois não apela essencial e soberanamente ao racional para tecer os seus conceitos, preconceitos, juízos, e o fortalecimento da propriocepção, uma vez que, ao vivenciarem a realidade do bairro, ao se relacionarem com os vizinhos que sofreram a violência, ao colocarem 
seus corpos em protesto contra uma determinada representação midiática, têm outra forma mais humanizada de tratar o acontecimento e de reportá-lo aos seus espectadores no canal de YouTube.

Entendemos que nas engrenagens das mídias comerciais também se apelam às linguagens emotivas e afetivas, como demonstrou consistentemente Sodré (2006), porém esses processos são camuflados por um verniz de racionalidade, a exemplo do trabalho de construção de credibilidade do discurso jornalístico que procura sempre se aderir a códigos ligados à faculdade da razão (vestuário, apresentação de dados, apuração de informações expostas como uma verdade unilateral, etc.).

Em uma entrevista à Revista Gambiarra, Raull Santiago, um dos fundadores do Papo Reto, explica que há um cuidado com o tipo de conteúdo que é postado nos canais do coletivo,

O Coletivo Papo Reto não circula imagens abertas de morte ou violações bizarras, o que acontece muito no Rio de Janeiro e outras páginas fazem muito comumente. Nossa política interna é de quando recebemos uma imagem, fazemos uma curadoria, avaliamos se pode ser postada na íntegra para expor uma situação, ou apenas parte dele. Quando tem uma denúncia muito grave ou quando a pessoa que filmou está expondo muito quem ela é, a gente articula com outras redes para minimamente tentar usar esse vídeo como prova de alguma forma em incidência de violação de direitos humanos. Quando são cenas de morte, a gente embaça, não expõe a pessoa, seja ela quem for, policial, morador ou jovem envolvido na criminalidade. Na maioria das vezes, mostramos só um chinelo, ou uma marca de sangue, algo que já dê pro público entender, sem termos que mostrar tudo. (...) A gente opina por não expor tanto dessa forma. (Flores, 2016)

Isto é, o Papo Reto busca outras formas de representação dos atores sociais presentes no território e vai além, ao separar uma parte das denúncias recebidas e encaminhar diretamente para os órgãos jurídicos competentes, como Ministério Público ou Corregedoria da Polícia Militar.

Em respeito às denúncias da atuação policial, uma postagem realizada pelo grupo no dia 10 de março de 2018 que revelava a execução sumária de dois jovens de identidade desconhecida na favela do Acari, na Zona Norte do Rio, ligando o crime aos policiais do $41^{\circ}$ Batalhão Militar, foi compartilhada pela vereadora Marielle Franco, assassinada ao sair de um evento promovido pelo movimento de mulheres negras da capital carioca. A vereadora, nascida no Complexo da Maré, se definia como "Mulher negra, cria da Maré e defensora dos Direitos Humanos" e teve forte atuação na CPI das Milícias, como assessora do presidente da comissão, o deputado Marcelo Freixo, do mesmo partido. 
O assassinato da vereadora, um crime politico, demonstra que as ameaças de morte e a criminalização dos movimentos sociais continuam a ser uma constante nos territórios periféricos. Os integrantes do Papo Reto, por conta de postagens como esta, em que questionam e revelam os excessos cometidos pelo poder policial, já sofreram ameaças, tanto na página do Facebook, como também por recados verbais e, além disto, foram persuadidos em uma delegacia a mostrar filmagens arquivadas no celular, o que não aconteceu, pois o membro do grupo que foi interpelado se recusou, por se tratar de uma ordem ilegal. Raull Santiago, em entrevista ao canal Pós-TV, avaliou que o momento politico é de perseguição e de distorção dos propósitos dos movimentos sociais.

É terrível o que está acontecendo com os movimentos hoje porque vende-se um discurso de que quando você fala contra algo que as pessoas que não moram na rua vivem, por exemplo, a violência policial, quando você questiona uma abordagem arbitrária da polícia, o contradiscurso vem dizer "ah você é a favor de traficante". E isso é muito baixo, muito raso, a gente questiona porque quer construir uma coisa melhor de fato. E há no Brasil, não apenas na favela, mas no campo atual político, do que a gente vive, a criminalização dos movimentos sociais a partir de você não poder expor a sua opinião, não poder se mobilizar e eu vejo isso como um retrocesso muito grande e a gente deve se unir, todos os tipo de comunicadores independentes, os projetos sociais, por mais que um ou outro talvez não se encontrem na linha de atuação, a gente deve botar esse problema da criminalização dos movimentos sociais acima de qualquer diferença que a gente possa ter, porque é algo que impacta diretamente no trabalho que cada um desenvolve. (PosTV, 2016, 2:08)

\section{Conclusão}

Ao analisar a atuação dos coletivos Tela Firme e Papo Reto frente as violências policiais, concluímos que estas formas de ativismo, mobilização social, e produção midiática alternativa atuam como um convite à reocupação dos espaços públicos da cidade, como resistência ao avanço dos fascismos e das barbaries norteados pelo pensamento conservador aqui descrito, que impactam nestes mesmos espaços, os tornando sem vida, demasiadamente higienizados, sem qualquer tipo de convívio democrático, sem atrativos para que haja encontros.

Defendemos neste trabalho que a ação comunicacional destes coletivos e a respectiva reivindicação pelos usos dos espaços públicos pela população, propõem uma recuperação das relações de solidariedade, aceitação das diversidades, ampliação dos encontros e de contato não-violento com o outro. Deste modo, há a oportunidade de construção de espaços, diálogos e manifestações que se oponham aos modos de violências reais e simbólicas que se dão nos espaços 
públicos das periferias, fazendo dos coletivos os agentes de um percurso contrário, espinhoso e cada vez mais perigoso: a ousadia de renovar as possibilidades de vínculos comunicativos, culturais, simbólicos e sociais nos territórios em disputa nas grandes cidades brasileiras.

Como dado vivo e atual do cenário das periferias das grandes capitais brasileiras, a ocupação dos espaços públicos tem sido objeto de interesse das instituições policiais, ao elegerem estes espaços como sítio de sua estratégia de ordenamento social; também das corporações imobiliárias, que veem nos centros precarizados oportunidades de exploração para novos negócios; e também - e principalmente - daqueles que habitam, há gerações, espaços precarizados dentro de um contexto de gentrificação das cidades (ver Paiva e Sodré, 2004). Ocupar e resignificar os espaços por meio de uma estratégia comunicacional que possa integrar juventude e memória, território e espaço virtual, instituições e associações, é o que consideramos um caminho promissor contra a barbárie da especulação política e econômica; e é o que observamos nos dois coletivos aqui analisados.

\section{Referências}

Al Jazeera. (16 de dezembro de 2015). A Bigger Brother (documentário). Recuperado de https://www.aljazeera.com/programmes/rebelgeeks/2015/12/biggerbrother-151216102151145.html

Amorim, C. R. T. C.; Sousa, M. C.; Mota, G.; e Silva, L. P. R. (2015). Mídias Alternativas na Amazônia: articulações de contrapoder na internet. Em XXXVIII Congresso Brasileiro de Ciências da Comunicação, 1-14. Rio de Janeiro: UFRJ. Recuperado de http://portalintercom.org.br/anais/nacional2015/resu mos/R10-3706-1.pdf

Aristóteles. (2007). Ética a Nicomaco. São Paulo: Ed. Martins Fontes.

Baitello Jr., N. (1999). Imagem e violência - A perda do presente. São Paulo em Perspectiva, 13(3), 81-84. Recuperado de http://www.scielo.br/scielo. php?script=sci_arttext\&pid=S0102-88391999000300011.

Buber, M. (2008). Sobre Comunidade. São Paulo: Ed. Perspectiva.

Chade, J. (18 de março de 2018). 1 em 6 ataques do mundo contra ativistas de direitos humanos acontece no Brasil. Estadão. Recuperado de http://brasil. estadao.com.br/noticias/geral,1-em-6-ataques-do-mundo-contra-ativistasde-direitos-humanos-acontece-no-brasil,70002231850

Da Agência Brasil. (27 de março de 2013). Critica à PEC das Domésticas é discurso da herança escravagista, diz professor de UnB. UOL Economía. Recuperado de https://economia.uol.com.br/empregos-e-carreiras/noticias/ 
redacao/2013/03/27/critica-a-pec-das-domesticas-e-discurso-da-herancaescravagista-diz-professor-da-unb.htm

Estrela, F. (2016). \#Parem de nos matar* (entrada de blog). Recuperado de https:// duduoriki.wordpress.com/2017/01/30/parem-de-nos-matar/

Filme narra chacinas que ocorreram na Região Metropolitana de Belém (6 de janeiro de 2015). Portal G1. Recuperado de http:/g1.globo.com/pa/ para/noticia/2015/01/filme-narra-chacinas-que-ocorreram-na-regiaometropolitana-de-belem.html

Flores, R. (14 de agosto de 2016). Raul Santiago, do coletivo Papo Reto, dá dicas de enfrentamento à violência policial. Revista Gambiarra. Recuperado de http://revistagambiarra.com.br/site/raul-santiago-do-coletivo-papo-retoda-dicas-de-enfrentamento-a-violencia-policial/

Franco, M. [mariellefranco]. (10 de março de 2018). O que está acontecendo agora em Acari é um absurdo! E acontece desde sempre! O $41^{\circ}$ batalhão da PM é conhecido como Batalhão da morte. CHEGA de esculachar a população! CHEGA de matarem nossos jovens! [tuit]. Recuperado de https://twitter. com/mariellefranco/status/972587390131896320

Gianotti, C. S. (2016). Experiência em Comunicação Popular no Rio de Janeiro ontem e hoje: uma história de resistência nas favelas cariocas. Rio de Janeiro: Núcleo Piratininga de Comunicação e Fundação Rosa Luxemburgo.

Gouvêa, L. (2018). Tela Firma, Gravando!: A produção audiovisual do coletivo Tela Firme no fomento dos vínculos culturais e comunicativos no bairro da Terra Firme, em Belém (PA) (dissertação de mestrado). Universidade Paulista, São Paulo, Brasil.

Han, B. C. (2012). Agonia do Eros. Petrópolis: Vozes.

Lei Complementar 150 (1 de junho de 2015). Recuperado de http://www.planalto. gov.br/ccivil_03/leis/lcp/lcp150.htm

Lobel, F. (1 de fevereiro de 2018). Justiça manda Doria tirar símbolos do programa SP Cidade Linda. Folha de S. Paulo. Recuperado de https://www1.folha. uol.com.br/cotidiano/2018/02/justica-manda-doria-tirar-simbolos-doprograma-sp-cidade-linda.shtml

Machado Da Silva, J. (2017). Raízes do Conservadorismo Brasileiro. Rio de Janeiro: Ed. Civilização Brasileira.

Paiva, R.; e Gabbay, M. (2016). Cidade, Afeto e Ocupações: ou a transfiguração do espaço político no Brasil contemporâneo. Em Anais do Congresso da Intercom. São Paulo: Universidade de São Paulo.

Paiva, R.; e Sodré. M. (2004). A cidade dos artistas. Rio de Janeiro: Mauad. 
Papo Reto. (3 de abril de 2015). Menino de 10 anos é assassinado no Alemão - 02/04/2015 (arquivo de vídeo). Recuperado de https://youtu.be/OdBSLcjwtIE

Pesquisa divulga dados alarmantes de violência contra o adolescente em Belém (7 de setembro de 2017). Portal G1. Recuperado de https:/g1.globo.com/pa/ para/noticia/pesquisa-divulga-dados-alarmante-de-violencia-contra-oadolescente-em-belem.ghtml

PosTV. (28 de abril de 2016). Raull Santiago do Coletivo Papo Reto conta da intimidação da PM no Complexo da Maré (arquivo de vídeo). Recuperado de https://www. youtube.com/watch?v=4Jp4cAoCk4Q

Puff, J. (30 de outubro de 2015). Como grupo de jovens virou referência internacional na denuncia de abusos policiais. BBC News Brasil. Recuperado de http://www.bbc.com/portuguese/noticias/2015/10/151028_coletivo_ papo_reto_alemao_jp

Relatório aponta que PM morto em chacina estava envolvido com milícia (30 de janeiro de 2015a). Portal G1. Recuperado de http:/g1.globo.com/pa/ para/noticia/2015/01/relatorio-aponta-que-pm-morto-em-chacina-estavaenvolvido-com-milicia.html.

Ricken, F. (2008). O Bem-viver em Comunidade: a vida boa segundo Platão e Aristóteles. São Paulo: Edições Loyola.

Sartre, J. P. (2005). Réflexions sur la Question Juive. Paris: Gallimard.

Sodré, M. (2017). Pensar Negô. Petrópolis: Vozes.

Sodré, M. (2006). As estratégias sensíveis: Afeto, mídia e política. Petrópolis: Vozes.

Sodré, M. (2009). A narração do fato: notas para uma teoria do acontecimento. Petrópolis: Vozes. 
